ISSN: 1980-055X

Recebido em: 30/04/2010

Aceito para publicação em: 02/08/2010

NOTA DE PESQUISA

\title{
A PESQUISA CLIMATOLÓgICA REALIZADA POR GEÓGRAFOS BRASILEIROS $^{37}$
}

\author{
Edson Soares Fialho ${ }^{38}$
}

\begin{abstract}
RESUMO
Os estudos climatológicos, no âmbito da Geografia, vêm ganhando importância, principalmente, após o início da década de 1990, período no qual foi realizado o 10 Simpósio Brasileiro de Climatologia Geográfica (SBCG), na UNESP-Rio ClaroSP (1992). As demais sedes do SBCG foram: Presidente Prudente-SP (1996), Salvador-BA (1998), Rio de Janeiro-RJ (2000), Curitiba-PR (2002), Aracajú-SE (2004), Rondonópolis-MT (2006) e Alto do Caparaó-MG (2008). Ao longo destes 18 anos, tanto o evento, quanto o número de pesquisas apresentadas cresceu de maneira consistente. Nesse sentido, o presente artigo, pretende identificar o perfil dos estudos de climatologia na ciência geográfica brasileira, ao longo da realização dos SBCG, assim como, refletir sobre as perspectivas e os entraves do desenvolvimento de novas vertentes de pesquisa até o momento desprezado pela comunidade geográfica que desenvolve estudos climatológicos. Para o desenvolvimento dessa pesquisa, utilizou-se o levantamento dos cadernos de resumo publicados nos eventos. A partir daí, os mesmos foram classificados de acordo com as categorias estipuladas: a) Campo térmico/conforto térmico; b) Qualidade do ar; c) Recurso hídrico/Secas/Impacto Pluvial; d) Estudos climáticos Regionais e locais; e) Dinâmica da atmosfera; f) Clima e agricultura; g) Clima e ensino; h) Outros (Neve, Vento, Saúde, Desertificação).
\end{abstract}

Palavras-chaves: Climatologia; Geografia; Simpósios e Geografia Física.

\begin{abstract}
The climatological studies in the context of geography, have been gaining importance, especially after the early 1990s, a period in which it was held the 1st Brazilian Symposium on Geographical Climatology (SBCG) at UNESP, Rio

37 Este trabalho se refere a parte da pesquisa bibliográfica do projeto de pesquisa de doutorado, cujo orientador: foi o Professor Doutor do Programa de Pós-Graduação em Geografia Física da Universidade de São Paulo-USP Tarik Rezende de Azevedo.

${ }_{38}$ Geógrafo. Doutor em Geografia Física pela Universidade de São Paulo. Professor Adjunto I da Universidade Federal de Viçosa. Coordenador do Laboratório de Biogeografia e Climatologia (BIOCLIMA). E-mail: fialho@ufv.br.
\end{abstract}


Claro-SP (1992). The remaining seats were the SBCG: Presidente Prudente-SP (1996), Salvador-BA (1998), Rio de Janeiro-RJ (2000), Curitiba-PR (2002), Aracaju-SE (2004), Rondonópolis-MT (2006) and Alto Caparaó-MG (2008). Over these 18 years, both the event, as many are displayed grew consistently. In that, this article aims to identify the profile of studies of climatology at the Brazilian geographical science, along the realization of SBCG, as well as reflect on the prospects and obstacles for developing new kinds of research so far neglected by the community geographical develops climatological studies. For the development of this research, we used the survey of books published summary of the events. From there, they were classified according to the categories stipulated: a) Field thermal / thermal comfort, b) Air quality; c) Water Resources / Drought/Rain Impact d) Regional and local climatic studies, e) Dynamic the atmosphere, f) Climate and agriculture; g) Climate and teaching; h) Other (Snow, Wind, health, desertification).

Key words: Climatology, Geography, Physical Geography and Symposium.

\section{Prólogo}

O desenvolvimento deste trabalho, referente à análise dos estudos de climatologia geográfica publicados nos anais dos Simpósios Brasileiros de Climatologia Geográfica (SBCG), tem seu início deflagrado, após uma primeira orientação/recomendação inicial do meu orientador de doutorado, Prof. Dr. Tarik Rezende de Azevedo, no ano de 2005, quando ingressei no Programa de Pósgraduação em Geografia Física da Universidade de São Paulo (USP).

A preocupação inicial era levantar o referencial teórico e os estudos de caso, relacionado à temática do campo térmico, o que gerou a publicação de um trabalho intitulado: Uma análise da produção climatológica, na ciência geográfica brasileira entre 1992 e 2004, no $6^{\circ}$ Simpósio brasileiro de climatologia geográfica, na qual alguns apontamentos foram expostos por alguns participantes. As sugestões foram de certa forma incorporada e novas questões afloraram, exigindo um aprofundamento da pesquisa, a partir de outras indagações, tais como: qual é a temática mais pesquisada no Brasil? Qual elemento do clima mais estudado? Em que escala climática os estudos mais utilizam?

Além disso, nos incentivou a continuar esta tarefa, o fato de no ano de 2000, durante a realização do IV SBCG, o fato de integrar a primeira gestão (como diretor tesoureiro e após secretário executivo) da atual Associação Brasileira de Climatologia (ABCLIMA), que teve como primeiro Presidente a Prof $^{a}$. Dr. Ana Maria de Paiva Macedo Brandão, até então minha orientadora do mestrado e coordenadora do laboratório de climatologia geográfica e análise ambiental (CLIMAGEO) da Universidade Federal do Rio de Janeiro (UFRJ).

Este envolvimento cativou-nos a acompanhar mais detidamente os tipos de trabalhos apresentados, durante os eventos da SBCG. Por conta disso, este artigo, além de fazer parte do levantamento bibliográfico para a tese de doutorado, acabou por esclarecer algumas questões que até então não tinham sido respondidas. 


\section{INTRODUÇÃO}

O desenvolvimento dos estudos ligados à Geografia Física, no Brasil, vem superando a visão descritiva da paisagem, procurando substituí-la por uma perspectiva integrativa. A Geografia "moderna" busca compreender e explicar a diferenciação de áreas da superfície da Terra, tendo como foco as relações do homem com a natureza. Essa nova abordagem nos estudos de Geografia Física pretende ultrapassar obstáculos inerentes ao paradigma positivista, que de certa forma propiciou o maior distanciamento entre os assuntos da natureza e dos homens.

Tal dicotomia, constatada por Mendonça et. al. (1999, p. 523), é superada por meio da utilização de novas proposições metodológicas, que afloram nas décadas de 1960 e 1970, quando se deslumbra novas perspectivas nos estudos geográficos. Inicialmente, desenvolvidas por Jean Tricart e George Bertrand. Neste novo contexto, são lançadas, por exemplo, as concepções de Geografia física global, Ecodinômica e Ecogeografia. Mais recentemente Bertrand e Bertrand (2007) propõem um aprimoramento de suas idéias iniciais, apresentando um modelo intitulado GTP (Geossistema, Território e Paisagem), que procura dar visibilidade ao processo dialético da dinâmica espacial.

Apesar disso, no final da década de 1980 a Geografia brasileira passa por um momento de grande mudança de paradigma, uma vez que, conforme relata Andrade (1989) a crise do capitalismo ao atingir o Brasil, criou condições para o surgimento de uma nova corrente de pensamento geográfico, denominada crítica ou radical. Esta nova linha de conduta ampliou sua influência no ambiente universitário e nas associações profissionais de Geógrafos, enquanto a corrente teórico-quantitativista perdeu prestígio, partindo para uma posição cada vez mais tecnocrática. Nesta década, os geógrafos, de acordo com suas posições teóricas e filosóficas, procuraram caminhos e explicações para a realidade que estava em mudança rápida e contínua.

Por conta disso, segundo Christofoletti (1985) os Geógrafos ligados a linha mais positiva criaram as condições para a realização dos Simpósios de Geografia Física Aplicada (SBGFA) para que a comunidade de pesquisadores brasileiros dedicados aos estudos da Geografia Física pudessem se reunir, debater e promover avanços nas discussões empíricas e teóricas.

O primeiro evento patrocinado por este grupo de geógrafos mais próximos das ciências naturais ocorreu no ano de 1984, na cidade de Rio ClaroSP, o SBGFA, que apesar de ser o maior encontro de estudiosos do ramo da Geografia Física, se encontra nas transformações e tendências dos estudos aplicados, refletindo sobremaneira as preocupações de fundo socioambientais e tecnológicas em vista do planejamento urbano-regional e ambiental.

Inicialmente, os estudos desenvolvidos em Geografia Física apresentados nos simpósios eram predominantemente especializados em sub-áreas: Geomorfologia, Climatologia e Biogeografia. Após, observa-se um crescente interesse pelas análises de interpretações integrativas, onde a perspectiva ambiental procura compreender os ambientes através da interação dos elementos de ordem físico-natural e socioeconômicos.

Apesar da perspectiva metodológica mais integrativa, nos estudos de Geografia Física, as sub-áreas do conhecimento geográfico procuraram trilhar seus caminhos. Tanto assim, que na década de 1990 surge o movimento de criação dos primeiros simpósios específicos. 
Numa perspectiva cronológica, primeiramente, o Simpósio Brasileiro de Climatologia Geográfica (SBCG) surge em Rio Claro, no ano de 1992. Posteriormente, em 1996 o Simpósio Brasileiro de Geomorfologia. Por fim, a última tentativa de se criar Simpósio Brasileiro de Biogeografia, porém este não seguiu em frente. Os dois primeiros conseguiram ter uma continuidade, que acabou por gerar duas novas entidades: Associação Brasileira de Climatologia (ABCLIMA), fundada no ano de 2000 e a União de Gemorfólogos Brasileiros (UGB), no ano de 1996. Esclareço, outrossim, que essa mesma tendência se verifica na chamada Geografia Humana, com a criação de Simpósios, como Geografia Agrária, Urbana e de Prática de Ensino.

Procurando entender as razões da criação de eventos específicos, Souza e Furlan (2005, p. 15402) afirmam que um dos motivos para que os estudiosos da Climatologia procurassem criar um SBCG fora inicialmente, incentivar os estudos das mudanças climáticas no seio da Geografia. Seguido do reconhecimento da necessidade de ampliar e caracterizar as pesquisas climatológicas no Brasil, a fim de melhor conhecer as características dos componentes climáticos e da dinâmica atmosférica, tanto espacial, nas escalas global, zonal, regional e local, como temporal, através dos estudos sobre a varialibidade, periodicidade e tendência.

Nesse contexto, o primeiro trabalho publicado por Fialho e Azevedo (2006) procurou responder algumas questões iniciais, a partir da leitura do estudo desenvolvido por Ribeiro (1982, p. 48). Dentre elas: a) A criação do Simpósio Brasileiro de Climatologia Geográfica (SBCG) favoreceu o desenvolvimento de novos centros de estudos do ramo da Climatologia na Ciência Geográfica? b) O SBCG ampliou o número de trabalhos publicados de Climatologia na ciência geográfica? c) Qual o perfil dos estudos climatológicos desenvolvidos pelos Geógrafos e d) Quais são as perspectivas e os entraves do desenvolvimento das pesquisas pela comunidade geográfica que desenvolve estudos climatológicos?

Algumas dessas perguntas foram respondidas, porém outras surgiram e por isto esta nova versão do trabalho ampliado traz um aprofundamento reflexivo das questões iniciais e do caminho que a climatologia brasileira está trilhando.

\section{MATERIAL E MÉTODOS}

Esta pesquisa, ao propor analisar o quadro atual da Climatologia, que vem sendo praticada atualmente, adotar-se-á os seguintes procedimentos. Procurar-se-á efetuar um levantamento bibliográfico geral que verse, sobre os aspectos históricos da Geografia do clima. Paralelamente, ao levantamento realizado junto aos cadernos de resumo dos Simpósios Brasileiros de Climatologia Geográfica (SBCG), realizados entre os anos de 1992 (Rio ClaroSP); 1996 (Presidente Prudente-SP); 1998 (Salvador-BA); 2000 (Rio de Janeiro-RJ); 2002 (Curitiba-PR); 2004 (Aracajú-SE); 2006 (Rondonópolis-MT) e 2008 (Alto do Caparaó-MG) onde se analisaram 1.108 resumos.

A opção pelos cadernos de resumos se justifica pelo fato de que, nem todos os eventos publicaram trabalhos completos, além do que nem todos os trabalhos enviados como resumo foram publicados na forma de trabalho 
completo. Como o intuito do trabalho, é identificar o que vem se pesquisando acredita-se que a análise não será prejudicada.

Após o levantamento dos títulos dos trabalhos, procurou-se classificá-los de acordo com as categorias listadas a seguir:

a) Campo térmico/conforto térmico;

b) Qualidade do ar;

c) Recurso hídrico/Secas/Impacto Pluvial;

d) Estudos climáticos Regionais e locais;

e) Dinâmica da Atmosfera;

f) Clima e Agricultura;

g) Clima e Ensino;

h) Outros: Neve, Vento, Saúde, Desertificação.

Além desta discriminação inicial, diferente do primeiro trabalho desenvolvido por Fialho e Azevedo (2006a e 2006b) foram inseridos outros itens, a fim melhor analisar a amostra de dados e substanciar a argumentação para algumas especulações a respeito das tendências dos estudos do clima pela ciência geográfica. Dentre estas, estão: Objeto de estudo (cujo intuito é identificar o elemento do clima que o trabalho aborda); Lugar (identificação da cidade e do estado de análise); Escala espacial (discriminada em: rural, costa, bacia de drenagem, urbano, estado, região e outros); Escala temporal (diária, mensal e anual) e por fim a identificação das instituições que participaram deste evento ao longo dos anos (foram consideradas apenas as instituições que apareceram pelo menos em 2 simpósios seguidos).

\section{RESULTADOS}

Refletindo sobre os obstáculos enfrentados pelos estudos climáticos, num primeiro momento, estes não teriam o porquê de existirem, uma vez que, o clima está presente no cotidiano da sociedade, influenciando diretamente grande parte das atividades exercidas pelo ser humano, como: agricultura, pecuária, lazer, transporte e turismo.

Além disso, hoje é possível constatar que algumas inovações tecnológicas são capazes de criar uma alteração climática em escala microclimática, como os condicionadores de ar, criando nesse sentido uma menor dependência dos elementos do clima.

Esse falso controle, aparentemente nos dá por alguns momentos a sensação de senhores do clima $^{39}$, porém isso não nos exime da ocorrência dos azares climáticos, regidos por sistemas atmosféricos de escalas superiores, decorrentes de forças físicas desencadeadas pelo desequilíbrio de radiação solar entre as diferentes latitudes, capazes de superar a resiliência da sociedade contemporânea.

O interesse pela questão do controle do clima é grande, pois a humanidade já conseguiu incorporar a natureza em todas as escalas: da zonal a micro, quanto ao aspecto simbólico, político e cultural, não havendo um só trecho do planeta que não esteja sob controle de uma entidade nacional. O não

\footnotetext{
39 Expressão utilizada como título da obra de Tim Flannery (2007). Em seu livro Flannery procura defender a hipótese de que o homem está alterando as condições climáticas e o que isso significa para o futuro do planeta.
} 
controle dos fenômenos climáticos, desperta como se fosse uma frustração. Daí a necessidade de se continuar a investir na obtenção de informações mais precisas, uma vez que ainda dependemos dos ciclos da atmosfera.

Isso nos auxilia na compreensão da popularização das questões climáticas, tanto assim que a obtenção de informações climatológicas tornou a previsão do tempo no Brasil em um negócio lucrativo, que alcança a cifra de 100 milhões de reais por ano (FIALHO, 2003, p. 422).

Além disso, é possível perceber o interesse pela temática, através do crescimento do número de sítios climatológicos, divulgando informações e esclarecendo dúvidas sobre aspectos específicos dos fenômenos atmosféricos. Como se constata, embora existam facilidades para a expansão dos estudos climáticos, no âmbito da Geografia estes ainda continuam tímidos, até a década de 1990, como pode ser visto, na Tabela 1, segundo o levantamento realizado por Brandão et. al. (1999, p.12).

A explicação para tal fato, não é fácil. Tanto assim, que esta mesma questão já foi posta por Zavatini (2000, p. 233). Segundo o autor, a produção científica atual é baixa, justamente agora que as conquistas da Meteorologia e da Informática são favoráveis ao desenvolvimento de novos estudos, abordagens e questionamentos.

Tabela 1. Levantamento do número de estudos climáticos publicados por Geógrafos

\begin{tabular}{l|c|c|c|c|c}
\hline \multicolumn{1}{c}{ Categoria } & Antes de 1970 & $\mathbf{1 9 7 0}$ & $\mathbf{1 9 8 0}$ & $\mathbf{1 9 9 0}$ & Total \\
\hline Campo Térmico & 1 & 5 & 20 & 59 & 85 \\
Qualidade do ar & 0 & 4 & 10 & 25 & 39 \\
Impacto Pluvial & 1 & 4 & 7 & 25 & 37 \\
Clima Urbano/Local & 2 & 5 & 6 & 5 & 18 \\
\hline
\end{tabular}

Fonte: Brandão, Russo e Fialho (1999, p.12).

Refletindo sobre a questão creio que as dificuldades poderiam perpassar pela formação dos Geógrafos, porém esta explicação é insuficiente, frágil e inconsistente. Isto porque, em pesquisas interdisciplinares voltadas às questões ambientais os Geógrafos conseguem ter uma inserção e se destacam em suas atividades profissionais.

Todavia, isto não quer dizer que há perda de espaço dos Geógrafos brasileiros para os demais profissionais: Engenheiros, Meteorologistas, Agrônomos e Arquitetos no desenvolvimento de estudos relacionados ao clima, como afirma Assis (2006a e 2006b). Essa observação da autora, apesar de verdadeira no aspecto quantitativo, merece ser repensada, uma vez que a diminuição da participação desse profissional em estudos do clima não significa que outros profissionais estejam desenvolvendo estudos climáticos de cunho geográfico ${ }^{40}$. Apenas significa que, agora outros profissionais despertaram interesse em desenvolver pesquisa com a temática climática, o que justifica o aumento do número de publicações relacionado ao assunto.

40 Segundo Conti (2001, p. 92) os estudos de climatologia geográfica preocupam-se, fundamentalmente, com seu papel na elaboração das paisagens e do mosaico espacial, no qual, é também, muito relevante o papel da história, da cultura e do modelo econômico (...) a climatologia feita pelos Geógrafos deve utilizar as situações quotidianas, vale dizer, a sucessão dos processos aerológicos e sinóticos para, a partir daí, determinar as características climáticas regionais e locais.

198

Ano 6 - Volume 6 - Junho/ 2010 
Embora o ato de criar novas técnicas e pensarem novas estratégias de abordagem climatológica não tem sido o forte dos Geógrafos climatólogos, salvo algumas exceções. Sendo mais prático, para não dizer fácil, importar e adaptar metodologia estrangeira ao invés de criar conceitos fundamentados em nossa realidade climatológica e adequados às verdadeiras necessidades do país (ZAVATINI, 2000, p. 230).

\section{A História dos SBCG ...}

A realização dos primeiros SBCG's foram cercadas de incertezas e desconfianças, tanto assim que o $2^{\circ}$ SBCG programado para o ano de 1994 não ocorreu. Muito em razão da própria forma como os eventos técnico-científicos são concebidos, no Brasil, muito dependentes da ação audaciosa de docentes, que podem se deparar com as dificuldades inerentes ao processo de elaboração e montagem do evento, muitas vezes desistem por falta de apoio e/ou estrutura da instituição, na qual os professores lecionam. Por conta disso, o 20 SBCG agendado para a Universidade Federal de Uberlândia não ocorreu.

Mas por ousadia de outros professores engajados, o $2^{\circ}$ SBCG ressurge em 1996, na UNESP de Presidente Prudente-SP, sob a organização do Prof. João Lima Sant Anna Neto. Apesar do hiato ocorrido, o número de publicações no Simpósio alcançou 91 trabalhos científicos, superior aos 75 apresentados no $1^{\circ}$ SBCG. Como se observa, o Simpósio ainda não tinha alcançado uma projeção nacional, por que o mesmo já tinha sido realizado no estado de São Paulo. Mas, em 1998, o mesmo amplia seus horizontes e se consolida no cenário nacional, quando 030 SBCG sob a organização da Prof ${ }^{a}$. Neyde Gonçalves da Universidade Federal da Bahia (UFBA) é realizado em Salvador, com o registrou um 119 trabalhos publicados.

No 40 SBCG subseqüente, realizado o Rio de Janeiro, sob o comando da Profa. Ana Maria de Paiva Macedo Brandão da Universidade Federal do Rio de Janeiro (UFRJ), no ano de 2000, tem a iniciativa de organizar uma entidade, juntamente com a colaboração de outros pesquisadores ${ }^{41}$, que participaram da reunião preparatória do $4^{\circ}$ SBCG, inicialmente denominada de Sociedade Brasileira de Climatologia, que hoje por questões de adequação a legislação, se chama Associação Brasileira de Climatologia (ABCLIMA), cuja primeiro presidente foi a Profa ${ }^{a}$ Ana Maria de Paiva Macedo Brandão, tendo como vicepresidente a Prof ${ }^{a}$ Neyde Gonçalves (UFBA).

A criação dessa associação tinha como objetivo dinamizar a comunidade de pesquisadores, potencializando trabalhos conjuntos, não deixando que apenas os encontros nacionais pudessem ser o único vetor catalisador de contatos e desenvolvimento de eventos de escala local e regional e da elaboração de um veículo de comunicação, agregação e divulgação de trabalhos.

No ano de 2002, o $5^{\circ}$ SBCG, realizado em Curitiba, sob a organização do Prof. Francisco Mendonça, o mesmo foi eleito, na sessão plenária, como o

\footnotetext{
41 Dentre os pesquisadores que participaram da gestação da idéia de se apresentar a proposta de criação da Sociedade Brasileira de Climatologia (SBCLIMA) estavam presentes os professores: Francisco Mendonça (UFPR), João Zavatini (UNESP-RC), João Sant anna Neto (UNESP-PP), Lucy Hack (PUC-Rio), Evando Barbiere (UFF) e a professora Ana Maria de Paiva Macedo Brandão (UFRJ), coordenadora do 40 SBCG em 2000. Junto a estes acompanhavam os preparativos mestrandos dos respectivos professores.
} 
segundo presidente da ABCLIMA. Neste evento, se registrou um número de 134 trabalhos. Porém, ainda a ABCLIMA não tinha se estruturado para poder ser a co-organizadora do evento, fato esse que viera a se concretizar no 60 SBCG (2004), realizado em Aracajú-SE, onde foram publicadas 197 contribuições científicas. Neste evento o Prof. João Lima Sant'Anna (UNESP-PP) foi empossado como novo presidente da ABCLIMA (2004-2006).

Em 2006, o evento foi sediado na região Centro-oeste, na Universidade Federal de Mato Grosso-Campus Rondonópolis (UFMT-RO), sob o comando dos Professores José Roberto Tarifa e Denise Maria Sette. E assim, como os demais, sempre registrando um incremento no número de participações $e$ de publicações, apresentando 215 trabalhos científicos. Além de eleger a nova Diretoria da ABCLIMA consagrou o Prof. José Bueno Conti (USP), novo presidente (2006-2008).

Por fim, o último evento, realizado em 2008, na cidade do Alto do Caparaó-MG, Washington Luiz Assunção da Universidade Federal de Uberlândia (UFU), apresentou um pequeno declínio em relação à tendência de aumento, com um total de 159 artigos. E quanto à diretoria da ABCLIMA, o novo presidente eleito foi o Prof. Emerson Galvani (USP).

Após uma apresentação do histórico dos eventos, os números de trabalhos apresentados ao longo dos 18 anos. Todavia, o número de contribuições neste evento ultrapassou o número de 1.000 , como pode ser visto na Tabela 2, de acordo com as categorias elencadas.

Tabela 2. Evolução Percentual Trabalhos por de acordo com temas apresentados no Simpósios Brasileiros de Climatologia (1992-2008).

\begin{tabular}{|c|c|c|c|c|c|c|c|c|c|}
\hline Categorias & 1992 & 1996 & 1998 & 2000 & 2002 & 2004 & 2006 & 2008 & Total \\
\hline $\begin{array}{c}\text { Número de trabalhos } \\
\text { publicados }\end{array}$ & $\begin{array}{c}75 \\
(100,0 \%)\end{array}$ & $\begin{array}{c}91 \\
(100,0 \%)\end{array}$ & $\begin{array}{c}119 \\
(100,0 \%)\end{array}$ & $\begin{array}{c}129 \\
(100,0 \%)\end{array}$ & $\begin{array}{c}134 \\
(100,0 \%)\end{array}$ & $\begin{array}{c}197 \\
(100,0 \%)\end{array}$ & $\begin{array}{c}215 \\
(100,0 \%)\end{array}$ & $\begin{array}{c}159 \\
(100,0 \%\end{array}$ & $\begin{array}{c}1.108 \\
(100,0)\end{array}$ \\
\hline $\begin{array}{l}\text { Campo térmico e } \\
\text { conforto térmico }\end{array}$ & $\begin{array}{c}7 \\
(9,0 \%)\end{array}$ & $\begin{array}{c}13 \\
(14,5 \%)\end{array}$ & $\begin{array}{c}20 \\
(17,0 \%)\end{array}$ & $\begin{array}{c}25 \\
(20,0 \%)\end{array}$ & $\begin{array}{c}24 \\
(18,0 \%)\end{array}$ & $\begin{array}{c}31 \\
(16,0 \%)\end{array}$ & $\begin{array}{c}30 \\
(14,0 \%)\end{array}$ & $\begin{array}{c}33 \\
(21,0 \%)\end{array}$ & $\begin{array}{c}183 \\
(17,0 \%)\end{array}$ \\
\hline Qualidade do ar & $\begin{array}{c}1 \\
(1,5 \%)\end{array}$ & $\begin{array}{c}3 \\
(3,0 \%)\end{array}$ & $\begin{array}{c}1 \\
(1,0 \%)\end{array}$ & $\begin{array}{c}4 \\
(3,0 \%)\end{array}$ & $\begin{array}{c}9 \\
(8,0 \%)\end{array}$ & $\begin{array}{c}8 \\
(4,0 \%)\end{array}$ & $\begin{array}{c}3 \\
(1,0 \%)\end{array}$ & $\begin{array}{c}0 \\
(0,0 \%)\end{array}$ & $\begin{array}{c}29 \\
(2,5 \%)\end{array}$ \\
\hline $\begin{array}{l}\text { Recursos hídricos, } \\
\text { secas e } \\
\text { impacto pluvial }\end{array}$ & $\begin{array}{c}24 \\
(32,0 \%)\end{array}$ & $\begin{array}{c}25 \\
(27,0 \%)\end{array}$ & $\begin{array}{c}40 \\
(34,0 \%)\end{array}$ & $\begin{array}{c}40 \\
(31,0 \%)\end{array}$ & $\begin{array}{c}30 \\
(23,0 \%)\end{array}$ & $\begin{array}{c}64 \\
(32,0 \%)\end{array}$ & $\begin{array}{c}48 \\
(22,0 \%)\end{array}$ & $\begin{array}{c}45 \\
(28,0 \%)\end{array}$ & $\begin{array}{c}316 \\
(28,0 \%)\end{array}$ \\
\hline $\begin{array}{l}\text { tudos cli } \\
\text { aionais }\end{array}$ & $\begin{array}{c}7 \\
(9,0 \%)\end{array}$ & $\begin{array}{c}20 \\
(22,5 \%\end{array}$ & $\begin{array}{r}18 \\
\left(15,0^{\circ}\right.\end{array}$ & $\begin{array}{c}15 \\
(12,0 \%)\end{array}$ & $\begin{array}{c}19 \\
(14,0 \%)\end{array}$ & $\begin{array}{c}32 \\
(16,0 \%)\end{array}$ & $\begin{array}{c}17 \\
(8,0 \%)\end{array}$ & $\begin{array}{c}7 \\
(5,0 \%)\end{array}$ & $\begin{array}{c}135 \\
(12,5 \%)\end{array}$ \\
\hline $\begin{array}{l}\text { Dinâmica da } \\
\text { atmosfera }\end{array}$ & $\begin{array}{c}5 \\
(7,0 \%)\end{array}$ & $\begin{array}{c}0 \\
(0,0 \%)\end{array}$ & $\begin{array}{c}14 \\
(12,0 \%)\end{array}$ & $\begin{array}{c}4 \\
(4,0 \%)\end{array}$ & $\begin{array}{c}7 \\
(5,0 \%)\end{array}$ & $\begin{array}{c}13 \\
(7,0 \%)\end{array}$ & $\begin{array}{c}15 \\
(7,0 \%)\end{array}$ & $\begin{array}{c}26 \\
(16,0 \%)\end{array}$ & $\begin{array}{c}84 \\
(8,0 \%)\end{array}$ \\
\hline Clima e Agricultura & $\begin{array}{c}6 \\
(8,0 \%)\end{array}$ & $\begin{array}{c}11 \\
(12,5 \%)\end{array}$ & $\begin{array}{c}4 \\
(3,0 \%)\end{array}$ & $\begin{array}{c}6 \\
(5,0 \%)\end{array}$ & $\begin{array}{c}12 \\
(9,0 \%)\end{array}$ & $\begin{array}{c}12 \\
(6,0 \%)\end{array}$ & $\begin{array}{c}8 \\
(4,0 \%)\end{array}$ & $\begin{array}{c}18 \\
(11,0 \%)\end{array}$ & $\begin{array}{c}77 \\
(7,0 \%)\end{array}$ \\
\hline Clima e Ensino & $\begin{array}{c}1 \\
(1,5 \%)\end{array}$ & $\begin{array}{c}4 \\
(4,0 \%)\end{array}$ & $\begin{array}{c}4 \\
(3,0 \%)\end{array}$ & $\begin{array}{c}6 \\
(5,0 \%)\end{array}$ & $\begin{array}{c}8 \\
(6,0 \%)\end{array}$ & $\begin{array}{c}10 \\
(5,0 \%)\end{array}$ & $\begin{array}{c}38 \\
(18,0 \%)\end{array}$ & $\begin{array}{c}5 \\
(3,0 \%)\end{array}$ & $\begin{array}{c}76 \\
(7,0 \%)\end{array}$ \\
\hline $\begin{array}{l}\text { Desertificação, Neve, } \\
\text { vento e saúde) }\end{array}$ & $\begin{array}{c}24 \\
(32,0 \%)\end{array}$ & $\begin{array}{c}15 \\
(16,5 \%)\end{array}$ & $\begin{array}{c}18 \\
(15,0 \%)\end{array}$ & $\begin{array}{c}24 \\
(20,0 \%)\end{array}$ & $\begin{array}{c}25 \\
(17,0 \%)\end{array}$ & $\begin{array}{c}27 \\
(14,0 \%)\end{array}$ & $\begin{array}{c}56 \\
(26,0 \%)\end{array}$ & $\begin{array}{c}25 \\
(16,0 \%)\end{array}$ & $\begin{array}{c}214 \\
(18,0 \%)\end{array}$ \\
\hline
\end{tabular}

Fonte: Cadernos de Resumo dos SBCG de 1992. 1996. 1998. 2000. 2002. 2004. 2006 e 2008.

Organizado por Edson Soares Fialho e Rosilene Aparecida do Nascimento (2010).

\section{Analisando o perfil dos trabalhos publicados no SBCG.}

Avaliando os trabalhos publicados por categoria, como pode ser observado na Tabela 2, o que nos chama atenção é o número de trabalhos com a temática relacionada à pluviosidade, alcançando um percentual corresponde a 
quase 30,0\% das publicações de cada SBCG. Esta observação é corroborada, quando verificamos na Tabela 3, que discrimina os estudos a partir dos elementos do clima.

Tabela 3. Elementos climáticos identificado nos trabalhos publicados no SBCG (1992-2008).

\begin{tabular}{lcccccccc}
\hline \multicolumn{1}{c}{ Objeto de Estudo } & 1992 & 1996 & 1998 & 2000 & 2002 & 2004 & 2006 & 2008 \\
\hline Precipitação & 37 & 56 & 61 & 71 & 49 & 117 & 102 & 93 \\
Temperatura do ar & 19 & 29 & 40 & 48 & 57 & 73 & 82 & 67 \\
Vento & 9 & 9 & 6 & 18 & 0 & 19 & 18 & 14 \\
Ozônio & 1 & 0 & 0 & 0 & 0 & 0 & 0 & 0 \\
Poluição do ar & 1 & 9 & 2 & 6 & 19 & 9 & 8 & 2 \\
Umidade & 5 & 14 & 1 & 3 & 1 & 1 & 22 & 22 \\
Nebulosidade & 1 & 1 & 0 & 2 & 1 & 2 & 3 & 1 \\
Pressão atmosférica & 0 & 1 & 0 & 5 & 2 & 2 & 0 & 0 \\
Nevoeiro & 0 & & 1 & 0 & 0 & 0 & 0 & 0 \\
Neve & 1 & 0 & 0 & 0 & 11 & 1 & 1 & 0 \\
\hline
\end{tabular}

Fonte: Cadernos de Resumo dos SBCG de 1992, 1996, 1998, 2000, 2002, 2004, 2006 e 2008. Organizado por Edson Soares Fialho e Rosilene Aparecida do Nascimento (2010).

A explicação para essa evidência pode estar relacionada ao fato da informação pluvial ser mais facilmente obtida junto às estações meteorológicas, em sua maioria auxiliares, sempre contém a presença de um pluviômetro de leitura diária a cada 24 horas, muito embora, a Organização Mundial de Meteorologia (OMM) recomende pelo menos três leituras diárias (12h00min, $18 \mathrm{~h} 00 \mathrm{~min}$ e $24 \mathrm{~h} 00 \mathrm{~min}$ - GMT).

Uma segunda explicação seria pelo fato de muitos estudos elaborarem sua própria rede de monitoramento, com equipamentos alternativos. $\mathrm{E} a$ terceira justificativa seria o fato das instituições públicas, como as Defesas Civis, Geo-Rio, COPASA Águas minerais de Minas S/A, dentre outras instituições ligadas ao setor de produção de Energia Elétrica ou Saneamento criarem suas próprias redes de monitoramento pluvial para atender suas demandas específicas.

Agora, o fato de existirem muitas redes de coleta de informações de instituições distintas, não significa que uma melhor cobertura espacial, uma vez que as mesmas podem ser coincidentes. Outro problema seria relacionado ao processo metodológico do registro da informação climática, o que pode inviabilizar a realização de um estudo de evento episódico, na escala horária ou mesmo diária.

Por exemplo, no Estado do Rio de Janeiro, a Secretaria Estadual de Rios e Lagoas (SERLA) tem uma rede de monitoramento pluviométrico, com leitura diária, às 9h00min (Horário de Brasília). O Instituto Nacional de Meteorologia (INMET) coleta suas informações junto às estações meteorológicas oficiais de primeira ordem e auxiliares em três momentos do dia (12h00min, 18h00min e 24h00min - GMT) e a Fundação GEO-Rio, apresenta monitora a chuva a cada 15 minutos.

Caso algum pesquisador necessite obter dados de intensidade da chuva no Estado do Rio de Janeiro, embora possa dispor e três redes de registros, o mesmo não poderá desenvolver uma pesquisa na escala de tempo diária, pois as metodologias de registro resultariam em diferenças entre os totais diários. Talvez, por conta disso, pode-se justificar o declínio das pesquisas relacionadas 
a água, no último SBCG, realizado em Rondonópolis, como também o pequeno número de estudos na escala diária se comparada a escala mensal e anual (Tabela 4).

A título de comparação grosseira, segundo o levantamento realizado por Ely (2006), que teve como base 152 títulos de trabalhos produzidos nos Programas de Pós-graduação em Geografia da USP, UFRJ, UNESP, UFS, UEM, UFPR e UFSC, constatou-se que grandes partes dos estudos se desenvolvem mais a temática do clima urbano, seguido da variabilidade pluvial, como pode ser visualizado na Tabela 5.

Tabela 4. Escala temporal identificada nos trabalhos publicados no SBCG (1992-2008).

\begin{tabular}{lcccccccc}
\hline $\begin{array}{c}\text { Escala } \\
\text { temporal }\end{array}$ & 1992 & 1996 & 1998 & 2000 & 2002 & 2004 & 2006 & 2008 \\
\hline Anual & 36 & 43 & 59 & 61 & 66 & 117 & 109 & 80 \\
Mensal & 1 & 9 & 1 & 11 & 9 & 13 & 14 & 16 \\
Diária & 3 & 5 & 9 & 20 & 12 & 22 & 31 & 22
\end{tabular}

Fonte: Cadernos de Resumo dos SBCG de 1992, 1996, 1998, 2000, 2002, 2004, 2006 e 2008.

Organizado por Edson Soares Fialho e Rosilene Aparecida do Nascimento (2010).

Tabela 5. Abrangência temática dos trabalhos.

\begin{tabular}{l|c}
\hline \multicolumn{1}{c|}{ Recortes Temáticos } & $\begin{array}{c}\text { Percentual de } \\
\text { trabalhos }\end{array}$ \\
\hline Clima urbano & $39,0 \%$ \\
Variabilidade pluvial & $28,0 \%$ \\
O Papel do clima na análise ambiental e da paisagem & $20,0 \%$ \\
Modelagem e estatística em climatologia geográfica & $8,0 \%$ \\
Teoria e método da climatologia geográfica & $5,0 \%$ \\
Total & $100,0 \%$ \\
\hline
\end{tabular}

Fonte: Ely, D. F. (2006)

Porém, o presente trabalho ao pensar em suas categorias, pensou-se em defini-las, a partir de um elemento ou tema, a fim de facilitar a divisão. Enquanto as informações produzidas por Ely (2006) foram agregadoras, sob perspectiva distinta. Portanto, tais números não são passíveis de comparação.

Quanto aos estudos relacionados ao campo térmico, este apresentou um grande crescimento, principalmente, nas áreas urbanas, fato que pode ser percebido, quando verificamos a escala espacial utilizada nos trabalhos publicados nos SBCG's (Tabela 6). E muito se deve ao aumento dos estudos de campo, ou seja, os experimentos de campo do térmico, se libertando das informações das estações meteorológicas, que ainda servem como padrão de calibração. Porém, não atendem aos estudos, uma vez que as medidas no campo urbano mensuram o ar dentro da cidade, e não fora do mesmo. 
Tabela 6. Escala espacial identificada nos trabalhos publicados no SBCG (19922008).

\begin{tabular}{l|c|c|c|c|c|c|c|c}
\hline \multicolumn{1}{c}{ Escala espacial } & 1992 & 1996 & 1998 & 2000 & 2002 & 2004 & 2006 & 2008 \\
\hline Rural & 6 & 7 & 3 & 4 & 4 & 6 & 0 & 12 \\
Costa & 5 & 1 & 6 & 4 & 5 & 10 & 0 & 3 \\
Bacia de drenagem & 6 & 7 & 5 & 13 & 11 & 23 & 12 & 19 \\
Urbano & 12 & 31 & 42 & 21 & 41 & 39 & 45 & 61 \\
Estado & 8 & 0 & 4 & 0 & 12 & 0 & 0 & 10 \\
Região & 10 & 5 & 9 & 5 & 5 & 4 & 1 & 2 \\
Montanha & 0 & 1 & 3 & 1 & 2 & 4 & 6 & 1 \\
Planície & 0 & 0 & 1 & 2 & 0 & 1 & 3 & 0 \\
Zonal & 0 & 0 & 0 & 0 & 0 & 0 & 1 & 0 \\
Outros & 1 & 1 & 0 & 69 & 20 & 89 & 96 & 35
\end{tabular}

Fonte: Cadernos de Resumo dos SBCG de 1992, 1996, 1998, 2000, 2002, 2004, 2006 e 2008. Organizado por Edson Soares Fialho e Rosilene Aparecida do Nascimento (2010).

Todavia, com este tipo de estudo necessita de uma operação de logística de equipamento e voluntários. Este tipo de trabalho vem sendo restrito no espaço, ou seja, cada vez mais são mais pontuais e num tempo de observação menor. Para resolver este problema, o melhor seria a utilização de sensores automáticos, contudo, em virtude do alto custo, os experimentos de campo, ainda requerem o uso de uma equipe numerosa, constituída quase sempre de graduandos.

Agora, outra explicação para o incremento dos estudos do campo térmico pode ser encontrada em Monteiro (2008, p. 76), que diz: "...que a cidade é o centro do espaço humanizado, num mundo simbolicamente organizado, o papel da mesma é conferir uma imagem ordenada do universo....".

Nesse sentido, a Geografia, como não poderia deixar de dispensar atenção ao estudo das cidades, que vem se mostrando, cada vez mais, a morada por excelência do homem na face da Terra. Dentre inúmeras razões, duas delas respondem por esse interesse: de um lado, pela concentração populacional, organização social e dinamização econômica; de outro, porque os espaços urbanizados são aqueles onde mais avultam as mudanças que o ser humano inflige ao meio natural (MONTEIRO, 2008, p. 78).

Com base no levantamento realizado pelo World Resource Institute, as áreas urbanas concentram $49,0 \%$ da população mundial. Isso equivale dizer que quase metade da população mundial ocupa uma área de 0,05\% da superfície da Terra (MASSON, 2006, p. 35) ${ }^{42}$. Porém, seu crescimento, ao longo do século XX, apresentou-se intenso e desigual espacialmente.

As cidades dos países tropicais registraram um ritmo mais intenso, em decorrência do processo de urbanização e industrialização tardia, muito embora, mesmo nos países desenvolvidos, as cidades concentrem um percentual de população superior (com $72,0 \%$ ) em relação aos países em desenvolvimento (com 42,6\%). Esses últimos apresentam um conjunto de população residente nas cidades maiores.

${ }^{42} \mathrm{O}$ valor da proporção de área urbana que ocupa a superfície da Terra não apresenta um consenso, variando entre 0,3\% (GUIDUGLI, 1984, p. 81) a 3,0\% (OKE, 1974). 
Em razão da preocupação com o aumento da população urbana no mundo, a partir do início do século XX, o estudo do clima das cidades vem ganhando importância. Contudo, apenas na década de 1970, começa a se identificar publicações de estudos de clima urbano em latitudes tropicais (JAUREGUI, 1973; 1993 e MONTEIRO, 1984).

No Brasil, de acordo com Brandão et. al. (2000), o interesse pelo estudo do clima urbano vem aumentando, desde a década de 1980, em função da problemática ambiental em nosso país.

Num esforço de sintetizar a situação atual da produção científica brasileira referente ao clima urbano, a partir de 1970, em um quadro preliminar, constata-se que grande parte dos trabalhos desenvolvidos privilegia as cidades das regiões Sul e Sudeste do Brasil, correspondente a 70,0\%, em média.

Tal informação é confirmada no trabalho desenvolvido por Zavatini (2002) quando o autor realiza um levantamento das dissertações e teses da USP que abordam o paradigma do ritmo.

Apesar do esforço de alguns pesquisadores de países tropicais, a distribuição espacial dos estudos de clima urbano continua concentrada nas cidades de latitudes médias, com cerca de 80,0\% (GOLDREICH, 1992; ARNIFIELD, 2003 e ROTH, 2007). Esse valor tem como base os levantamentos realizados a partir do ano de 2000, conforme pode ser visto na Tabela 7.

Cabe destacar que os estudos referentes ao levantamento de trabalhos publicados acerca da temática urbana contabilizam apenas os trabalhos publicados em língua inglesa, nos periódicos de referência internacional sobre o assunto.

Esse critério desconsidera o aumento da produção brasileira, que registrou um incremento do número de publicações, após a criação do SBCG, conforme estudos realizados por Fialho e Azevedo (2006). Os mesmos autores identificaram que, ao longo de 18 anos de realização do evento, 1.108 contribuições científicas foram apresentadas.

Vale salientar que essa produção, em grande parte, é mantida por graduandos e pós-graduandos em fase de desenvolvimento de pesquisa. Isso quer dizer que são poucos os trabalhos completos apresentados. Caso esse critério fosse considerado, o número de publicações seria inferior.

Segundo Fialho (2006), embora o crescimento da produção científica tenha sido considerável, a concentração do número de publicações na região Sudeste é de cerca de 50,0\%, seguido pela região Sul, com 20,0\%, conforme pode ser visto na Tabela 8 . Devido a isso, o desenvolvimento do estudo climatológico ainda é limitado, uma vez que muitas realidades ainda são desconhecidas ou pouco estudadas.

Comparando os dados os dados da Tabela 2 e a Tabela 8, nos permite observar, que o local de realização dos SBCG influenciou a participação das contribuições regionais, assim como ampliou o número de trabalhos publicados ao longo do tempo, exceto o último evento no Alto Caparaó-MG, muito em razão das dificuldades de acesso a localidade. Além disto, o evento também se consolida junto às instituições universitárias, uma vez que o número de participantes vem aumentando, como pode ser visto na Tabela 9, como também da participação de grupos de pesquisas, que se concretizam através da criação de laboratórios de pesquisas (Tabela 10). 
Tabela 7. Trabalhos de revisão bibliográfica de clima urbano após o ano de 2000.

\begin{tabular}{|c|c|}
\hline Referência & Tópico \\
\hline Sturman, A. P. (2000) & $\begin{array}{l}\text { Revisão dos trabalhos de ilha de calor (mitigação. efeitos } \\
\text { implicações). }\end{array}$ \\
\hline $\begin{array}{l}\text { Brandão et. al. (2000) } \\
\text { Mendonça, F. (2003) }\end{array}$ & $\begin{array}{l}\text { Revisão dos trabalhos de clima urbano publicados até } 1990 . \\
\text { Evolução dos estudos de clima urbano no Brasil. }\end{array}$ \\
\hline Mckendry, I. G. (2003) & $\begin{array}{l}\text { Levantamento dos trabalhos de clima urbano publicados entre } 1998 \text { e } \\
2003 \text {. }\end{array}$ \\
\hline Arnfield, A. J. (2000) & Levantamento de estudos de clima urbano publicados em 1998. \\
\hline Arnfield, A. J. (2001a) & $\begin{array}{l}\text { Revisão dos estudos relacionados a canyons urbanos publicados em } \\
1999 .\end{array}$ \\
\hline Arnfield, A. J. (200 & $\begin{array}{l}\text { Revisão dos estudos relacionados ao clima urbano publicados em } \\
2000 \text {. }\end{array}$ \\
\hline $\begin{array}{l}\text { Zav } \\
\text { Arn } \\
\text { Arn }\end{array}$ & $\begin{array}{l}\text { são dos estudos que consideraram o paradigma do ritmo. } \\
\text { são dos trabalhos de clima urbano publicados entre } 1990 \text { e } 2002 \text {. } \\
\text { são dos trabalhos de clima urbano publicados em } 2003 .\end{array}$ \\
\hline & $\begin{array}{l}\text { Revisão de teses que utilizaram a perspectiva do ritmo entre } 1944 \text { e } \\
2003 \text {. }\end{array}$ \\
\hline $\begin{array}{l}\text { o, E. S. e Azevedo, } \\
(2006)\end{array}$ & Revisão dos estudos de clima publicados entre 1992 e 2004 nos SBCG. \\
\hline Fialho, E. S. (2006) & clima publicados entre 1992 e 2006 nos SBCG. \\
\hline $\begin{array}{l}\text { Souch, C. e Grimmond, } \\
\text { S. (2006) }\end{array}$ & Revisão dos trabalhos de clima urbano publicados em 2004 e 2005. \\
\hline $\begin{array}{l}\text { Roth, M. (2007) } \\
\text { Kanda, M. (2007) }\end{array}$ & $\begin{array}{l}\text { abalhos de clima urbano em regiões sub-tropicais. } \\
\text { dos progressos em trabalhos de meteorologia urbana. }\end{array}$ \\
\hline
\end{tabular}

Fonte: Fialho, E. S. (2009, p. 21).

Tabela 8. Trabalhos publicados de acordo com cada região/área do Brasil no SBCG (1992-2008).

\begin{tabular}{l|c|c|c|c|c|c|c|c}
\hline \multicolumn{1}{c}{ Regiões } & 1992 & 1996 & 1998 & 2000 & 2002 & 2004 & 2006 & 2008 \\
\hline Sul & $25,0 \%$ & $24,0 \%$ & $10,0 \%$ & $18,0 \%$ & $35,0 \%$ & $21,0 \%$ & $23,0 \%$ & $20,0 \%$ \\
Sudeste & $54,0 \%$ & $50,0 \%$ & $47,0 \%$ & $62,0 \%$ & $47,0 \%$ & $46,0 \%$ & $38,0 \%$ & $52,0 \%$ \\
Nordeste & $8,0 \%$ & $4,0 \%$ & $26,0 \%$ & $9,0 \%$ & $7,0 \%$ & $17,0 \%$ & $9,0 \%$ & $10,0 \%$ \\
Centro-Oeste & $5,0 \%$ & $13,0 \%$ & $1,0 \%$ & $8,0 \%$ & $8,0 \%$ & $12,0 \%$ & $25,0 \%$ & $12,0 \%$ \\
Norte & $7,0 \%$ & $8,0 \%$ & $15,0 \%$ & $1,0 \%$ & $3,0 \%$ & $2,0 \%$ & $5,0 \%$ & $5,0 \%$ \\
Brasil & $1,0 \%$ & $1,0 \%$ & $1,0 \%$ & $2,0 \%$ & $0,0 \%$ & $2,0 \%$ & $0,0 \%$ & $1,0 \%$ \\
\hline
\end{tabular}

Fonte: Cadernos de Resumo dos SBCG de 1992, 1996, 1998, 2000, 2002, 2004, 2006 e 2008.

Organizado por Edson Soares Fialho e Rosilene Aparecida do Nascimento (2010).

Ainda analisando a Tabela 8, identifica-se que as Universidades com maior participação ao longo destes anos sempre foram: USP, UFU, UNESPPresidente Prudente, UNESP-Rio Claro, UFRJ. Entre estas, a que mais cresceu foi a UNESP-Presidente Prudente e a UFU, enquanto a UNESP-Rio Claro, instituição que organizou o $1^{\circ}$ SBCG, decaiu de maneira preocupante.

Em um segundo grupo se encontra universidades que, embora tenham uma participação percentual um pouco menor, estas são consistentes, e todas apresentam a presença de um laboratório de pesquisas climatológicas: UEM, UFSC, UFJF, UFPR, UNICAMP e UFMG (Tabela 10).

Um terceiro grupo possível de identificar, é o desaparecimento de instituições nos SBCG's. Isto porque, quase sempre era representado, por um professor especialista em climatologia, quando este se aposenta ou muda de Universidade, a instituição deixa de aparecer, como o caso da PUC-Rio e UNISC. Outra causa pode explicar a não participação circunstancial nos eventos, é a distância, como pode se constatar com a: UFS, UFRN, UFPEL, UFCE, UFBA, UFPI, UFPB UFMS, UNB e UFAM. 
Por fim, um segmento, caracterizado como emergentes, pois resultam da política de expansão horizontal das Universidades (federais e estaduais) brasileiras, que refletem na abertura de novos cursos de Geografia (e, por conseguinte a contratação de novos professores) ou da ampliação do número de vagas, via inauguração de novos campis. Nesse contexto, a UNESP-Ourinhos, UFG, UFSM, UFMT, PUC-SP, Uni-BH, UEFS, e UFV. Cabe destacar, que o aparecimento de instituições particulares não ocorre pelas mesmas razões citadas acima. Mas, pelo simples fato destas instituições necessitarem e requerem profissionais mais qualificados. Estas também são obrigadas a manterem laboratórios, o que abre espaço para criação de novos grupos de pesquisa.

Tabela 9. Instituições de Ensino Superior e a freqüência de participação no SBCG (1992-2008).

\begin{tabular}{lccccccccccc}
\hline Instituições & 1992 & 1996 & 1998 & 2000 & 2002 & 2004 & 2006 & 2008 & TOTAL \\
\hline UNESP-RC & 14 & 12 & 16 & 15 & 7 & 10 & 6 & 1 & 81 \\
USP & 6 & 11 & 16 & 16 & 6 & 7 & 5 & 9 & 76 \\
UNESP-PP & 4 & 14 & 1 & 6 & 16 & 15 & 6 & 13 & 75 \\
UFRJ & 1 & 3 & 7 & 12 & 15 & 5 & 6 & 8 & 57 \\
UFU & 2 & 10 & 4 & 10 & 7 & 15 & 19 & 29 & 96 \\
UEM & 1 & 4 & 3 & 8 & 8 & 11 & 4 & 6 & 45 \\
UFSC & 1 & 5 & 1 & 2 & 5 & 0 & 1 & 2 & 17 \\
UFPB & 1 & 1 & 1 & 2 & 0 & 2 & 0 & 4 & 11 \\
UFJF & 1 & 0 & 7 & 0 & 2 & 7 & 5 & 1 & 23 \\
UFMG & 1 & 2 & 6 & 0 & 2 & 2 & 0 & 0 & 13 \\
UEL & 3 & 0 & 1 & 1 & 1 & 0 & 0 & 1 & 7 \\
PUC-RIO & 1 & 1 & 1 & 1 & 1 & 6 & 0 & 0 & 11 \\
UFSM & 1 & 0 & 0 & 0 & 0 & 11 & 8 & 7 & 27 \\
UFPA & 7 & 5 & 13 & 1 & 0 & 0 & 0 & 0 & 26 \\
UFRN & 3 & 0 & 0 & 0 & 0 & 0 & 2 & 0 & 5 \\
UFPEL & 1 & 0 & 0 & 0 & 1 & 0 & 0 & 0 & 2 \\
UFCE & 1 & 0 & 0 & 0 & 1 & 0 & 0 & 3 & 5 \\
UNB & 1 & 1 & 0 & 2 & 0 & 3 & 3 & 3 & 13 \\
UFAM & 0 & 1 & 0 & 2 & 0 & 0 & 0 & 5 & 7 \\
UFMS & 0 & 6 & 0 & 2 & 0 & 2 & 0 & 0 & 10 \\
UFBA & 0 & 2 & 6 & 1 & 0 & 0 & 1 & 1 & 11 \\
UFS & 0 & 0 & 1 & 2 & 1 & 15 & 4 & 0 & 23 \\
UFPI & 0 & 0 & 1 & 1 & 1 & 4 & 0 & 0 & 7 \\
UNISC & 0 & 0 & 1 & 1 & 1 & 1 & 0 & 0 & 4 \\
UFPR & 0 & 4 & 4 & 6 & 10 & 6 & 9 & 1 & 40 \\
UFMT & 0 & 1 & 0 & 3 & 2 & 5 & 14 & 7 & 32 \\
UNICAMP & 0 & 0 & 1 & 1 & 1 & 5 & 4 & 6 & 18 \\
UEFS & 0 & 0 & 3 & 0 & 0 & 0 & 5 & 1 & 9 \\
UNI-BH & 0 & 0 & 0 & 0 & 2 & 1 & 2 & 1 & 6 \\
UFG & 0 & 1 & 0 & 1 & 2 & 20 & 12 & 6 & 42 \\
UNESP-OR & 0 & 0 & 0 & 0 & 0 & 0 & 6 & 7 & 13 \\
PUC-SP & 0 & 0 & 0 & 0 & 0 & 0 & 1 & 2 & 3 \\
UFV & 0 & 0 & 0 & 0 & 0 & 0 & 1 & 3 & 4 \\
\hline
\end{tabular}

Fonte: Cadernos de Resumo dos SBCG de 1992, 1996, 1998, 2000, 2002, 2004, 2006 e 2008. Organizado por Edson Soares Fialho e Rosilene Aparecida do Nascimento (2010). 
Tabela 10. Laboratórios de Climatologia inseridos nos Departamentos de Geografia das Universidades Federais/Estaduais do Brasil.

\begin{tabular}{lc}
\hline \multicolumn{1}{c|}{ Laboratórios } & Instituição \\
\hline LCB - Laboratório de climatologia e biogeografia & USP \\
LCGEA - Laboratório de climatologia geográfica & UNB \\
LCAA - Laboratório de climatologia e análise ambiental & UFJF \\
LCRH - Laboratório de climatologia e recursos Hídricos & UFU \\
LABOCLIMA - Laboratório de climatologia & UFPR \\
CLIMAGEO - Laboratório de Climatologia geográfica e análise ambiental & UFRJ \\
Laboratório de climatologia & UFMT \\
LABCLIMA - Laboratório de climatologia aplicada & UFSC \\
LCRH - Laboratório de climatologia e recursos hídricos & UFC \\
Laboratório de climatologia & UNESP-RC \\
\hline
\end{tabular}

Fonte: Cadernos de Resumo dos SBCG de 1992, 1996, 1998, 2000, 2002, 2004, 2006 e 2008.

Organizado por Edson Soares Fialho e Rosilene Aparecida do Nascimento (2010).

Analisando a variabilidade dos eixos temáticos ao longo do período em questão, constata que o clima urbano predomina, enquanto a temática: clima e agricultura é por sua vez, muito desvalorizada por geógrafos, mesmo tendo esta categoria uma grande contribuição nas discussões referentes à Reforma Agrária neste país.

Ao longo dos eventos realizados os trabalhos com a temática de clima e agricultura, nunca ultrapassou a $10,0 \%$ dos trabalhos submetidos. Essa parca contribuição desperta uma curiosidade. Levantando alguns outros eventos ligados a Sociedade Brasileira de Meteorologia (SBMET), se constata que os estudos de clima e agricultura são mais uma preocupação dos engenheiros Agrícolas, Biólogos e Meteorologistas, que tem eventos específicos para tal temática, com, por exemplo, o congresso de agroclimatologia, organizado pela SBMET.

Nessa mesma linha de estudos desvalorizados estão os estudos relacionados a qualidade do ar, onde apenas no $6^{\circ}$ SBCG acusou mais de 5,0\% das publicações ligadas a área. Apesar disso, o problema desse tipo de estudo perpassa pela disponibilidade da informação. Ele estará presente apenas em cidades, onde os órgãos ambientais estaduais ou Universidades consigam monitorar a qualidade do ar, caso contrário é muito difícil de produzir este tipo de dado, por conta dos custos dos aparelhos de mensuração que apresentam uma grande sofisticação tecnológica, o que cria outro problema, que é a espacialização dessa rede, que se tornam restritos por não se ter muitos pontos de monitoramento da qualidade do ar. Algumas cidades do Brasil, apenas apresentam uma estação de qualidade do ar, que se localizam, geralmente, nos locais de maior contaminação.

Quanto à temática do ensino, a muito não conseguia ter uma expansão, embora a discussão do meio ambiente seja um tema freqüente hoje nos bancos escolares. O que pode estará acontecendo? Será que há associação das enchentes, fenômeno recorrente nas grandes cidades pode ser vinculada a temática de estudos de os problemas ambientais? 
No entanto, no 70 SBCG, houve um grande acréscimo nas publicações relacionado ao ensino, que quase quadruplicou em relação ao $6^{\circ}$ SBCG. Apesar de benéfico, questões surgem, quando se verifica que a maior parte dos trabalhos é de professores universitários que estão publicando as atividades desenvolvidas junto às disciplinas relacionadas à temática do clima ou meio ambiente.

Porque, somente, depois de 18 anos existe uma preocupação maior com o tema, vislumbrado pelo número de trabalhos publicados? Será um tema de modismo? Será uma resposta as exigências de publicações por parte dos órgãos avaliadores das instituições universitárias, que hoje lançam mão do critério de produtividade para avaliar um curso? Ou será que a distância entre o conhecimento acadêmico e escolar é o ponto de incômodo, que está gerando uma maior preocupação por parte dos estudiosos, que estão a procurar refletir uma nova maneira de se trabalhar com os temas ligados a temática do clima de forma mais inteligível. Infelizmente, hoje não há respostas, que apenas apareceram com o tempo.

Os estudos referentes à dinâmica atmosférica, definitivamente nunca tiveram grande visibilidade e preocupação por parte dos pesquisadores participantes do SBCG. Isso, talvez em razão da sua forte vinculação ao entendimento dos sistemas atmosféricos e a interpretação dos mesmos sobre as cartas sinóticas e imagens de satélites, que é muito trabalhado pelos meteorologistas. Mas essa argumentação se torna frágil, posto que a disponibilidade das cartas sinóticas e imagens de satélite, não causam obstáculo para o desenvolvimento do estudo. E outra, onde fica a idéia da análise rítmica apregoada por Monteiro (1999, p. 13), que defende a idéia do ritmo com essência do fenômeno climático?

Em relação aos estudos em escala local, constata-se hoje um predomínio referente ao excepcional, episódico, nos estudos do clima no âmbito da Geografia, enquanto os estudos de escala regional, mais valorizados no início do século $X X$ são quase que inexistentes. Tal mudança, talvez possa encontrar explicação na dificuldade de se operacionalizar esse tipo de estudo? Ficando restrito aos institutos de pesquisa.

Quanto a categoria outros, onde se aglomerou as temas de neve, vento, desertificação e saúde, fica claro ao visualizar a Tabela 3 essa categoria apresentava um crescimento lento ao longo da realização dos SBCG, no entanto, no 70 SBCG, assim como a temática do ensino cresceu muito, o tema relacionado clima e saúde foi responsável por 40,0\%, número esse que dobrou em relação ao $6^{\circ}$ SBCG. Pelo fato de haver uma continuidade destes trabalhos, que tiveram um incremento significativo, pode-se afirmar que a questão relacionada à qualidade de vida nos meios urbanos está ocasionando uma maior preocupação com a saúde, o que não necessariamente acarreta uma volta da orientação médico-sanitarista aos estudos climáticos, até mesmo porque os tempos são distintos.

Em relação a temática da desertificação e da neve, no Brasil, observa-se que são tímidos, até mesmo pela restrição espacial dos fenômenos ao longo do território nacional, porém não menos importante, pois as repercussões sócioespaciais dos mesmos vem provocando uma maior preocupação por parte das autoridades. 


\section{CONSIDERAÇÕES FINAIS}

Uma preocupação comum, a maioria dos estudos, incorpora a dimensão social na interpretação da análise geográfica do clima. Isto significa, necessariamente, compreender a repercussão dos fenômenos atmosféricos na superfície terrestre, composta por grupos humanos, que criam espaços geográficos distintos, mais ou menos vulneráveis a ação dos fenômenos climáticos.

Mas, ao final dessa jornada, novos questionamentos afloram, sem ao menos conseguirmos responder todas as demais levantadas no início do trabalho. Por exemplo, apesar do aumento do número de publicações nos SBCG, o que pode ser considerado positivo, e até mesmo um reflexo da existência da ABCLIMA. Ainda assim, nos preocupa a falta de estudos em escala regional. Embora as dificuldades inerentes ao desenvolvimento deste tipo de pesquisa, a ABCLIMA deve ser o catalisador deste esforço, promovendo forma de interação e trabalhos conjuntos entre laboratórios de pesquisa de instituições diversas.

Um segundo apontamento se refere a continuidade dos estudos. De maneira geral, os trabalhos publicados em grande parte são de autoria de acadêmicos de graduação, em estágio inicial. Infelizmente, os mesmos não têm uma continuidade. Muito embora, o próprio evento seja um ambiente de experimentação para muitos graduandos, que participam dos novos laboratórios de estudos climáticos, que surgiram a partir da década de 1990, Em algumas universidades, como: UFPR, UFJF, UFRJ, UFU, UFSM, UFS, UFBA, UFMT, além da USP e UNESP (Rio Claro e Presidente Prudente) pólos centrais de especialização dos professores das universidades supracitadas ao nível de pós-graduação (Doutorado ou Mestrado).

A preocupação se fundamenta, na constatação da escassa participação de pós-graduandos. O que isto reflete? A falta de candidatos para os cursos de pós-graduação?; b) Há um desinteresse pela temática: clima; c) Ou será que ainda existem poucos profissionais habilitados a orientar pesquisas na área de climatologia nos programas de pós-graduação no Brasil?

Acredito que nenhuma das indagações anteriores seja capaz de justificar uma participação reduzida dos pós-graduandos, assim como a divulgação ínfima de trabalhos completos.

Porém, a pergunta encontra um início de resposta, quando analisamos as mudanças sofridas nos programas de pós-graduação. Até meados da década de 1990, o período de realização do mestrado era de 48 meses (4 anos) e o doutorado de 72 meses ( 6 anos) Agora, os programas sob orientação da CAPES determinam, cerca de 24 meses ( 2 anos) para o mestrado e 48 meses ( 4 anos) para o doutorado. Como forma de controle, a CAPES inseriu o critério de prazo de defesa. Caso algum discente ultrapasse o seu limite de tempo, o programa pode ser penalizado com a perda de recursos, bolsas e até de nota do programa.

A conseqüência disto é a perda de qualidade, principalmente, no mestrado, que não tem mais tempo para um maior amadurecimento intelectual. Acarretando, muitas das vezes pesquisas em períodos mais curtos, a fim de obter mais tempo para análise dos dados. Tanto é real, que segundo levantamento realizado por Fialho (2009) se constatou que estudos de dissertação de mestrado, que antes procuravam abordar pelo menos duas estações sazonais distintas, a fim de melhor caracterizar o campo térmico, 
hígrico, dentre outros objetos de estudos em condições de tempo características de estações extremas (verão e inverno), ou pelo menos de transição (transição). Agora, apenas um experimento é considerado suficiente para analisar e avaliar o objeto de estudo.

A conseqüência desta adaptação é o retrocesso da ciência, é a perda de consistência e uma estagnação do conhecimento, que cada vez é menos desafiado frente aos empecilhos da vida acadêmica.

\section{Agradecimentos}

Ao Professor Luis Alberto Martins da Universidade de Feral de Juiz de Fora (UFJF) por nos permitir o acesso aos cadernos de resumos do 10 SBCG (1992). A Geógrafa Rosilene Aparecida do Nascimento (ex-bolsista de graduação da UFV do curso de Geografia), que nos auxiliou na contagem e discriminação dos trabalhos analisados. E ao Professor Tarik Rezende de Azevedo, um pesquisador perspicaz, por sua orientação, companheirismo e toda compreensão, os meus sinceros agradecimentos.

\section{REFERÊNCIAS BIBLIOGRÁFICAS}

ANDRADE, M. C. Caminhos e descaminhos da geografia. Campinas: Papirus, 1989.

ARNIFIELD, A. J. Two decades of urban climate research: A review of turbulence, exchanges of energy and water, and the urban heat island. International journal of climatology, London, v. 23, n. 1, p. 1-26, 2003.

ASSIS, E. S. Urban climate applications on city planning: Reviewing the Brazilian studies in: INTERNATIONAL CONFERENCE ON URBAN CLIMATE, ICUC, 6, Proceedings..., Göteborg, Sweden, p. 663-666, 2006a.

ASSIS, E. S.. Aplicações da climatologia urbana no planejamento da cidade: Revisão dos estudos brasileiros. Revista rua. Salvador, n. 9, p. 20-25, 2006b.

BERTRAND, G.; BERTRAND, C. A natureza na geografia: Um paradigma de interface. in: PASSOS, M. M. (org.).: Uma Geografia transversal e de travessias: O meio ambiente através dos territórios e das temporalidades. Maringá: Massoni, p. 81-97, 2007, 332p.

BRANDÃO, A. M. P. M.; RUSSO, P. R.; FIALHO, E. S. Planejamento e clima urbano. Revista de pós-graduação em geografia. Rio de Janeiro, v. 4, p. 9-23, 2000.

CHRISTOFOLETTI, A. Simpósio de geografia física aplicada. Boletim de geografia teorética. Rio Claro, v. 15, n. 29-30, p. 9-28, 1985.

CONTI, J. B. Geografia e climatologia. Revista geousp. São Paulo, n. 9, p. 91$95,2001$. 
ELY, D. F. Delineamentos teóricos-metodológicos da climatologia geográfica brasileira a partir da análise das teses e dissertações produzidas nos programas de pós-graduação em Geografia. In: SIMPÓSIO BRASILEIRO DE CLIMATOLOGIA GEOGRÁFICA, 7., 2006. Rondonópolis. Anais... Rondonópolis: UFMT, cd-rom.

FIALHO, E. S. A percepção do clima através da noção do ritmo. In: ENCONTRO NACIONAL DE PRÁTICA DE ENSINO DE GEOGRAFIA, 7, Espírito Santo, Anais... Espírito Santo: UFES, p. 422-430, 2003. cd-rom.

FIALHO, E. S.; AZEVEDO, T. R. Uma análise da produção climatológica, na ciência geográfica brasileira entre 1992 e 2004. in: SIMPÓSIO BRASILEIRO DE CLIMATOLOGIA GEOGRÁFICA, 7, 2006a. Rondonópolis, Anais..., Mato Grosso: UFMT, 2006, cd-rom.

FIALHO, E. S. Uma análise da produção climatológica, na ciência geográfica brasileira entre 1992 e 2006. in: SEMINÁRIO DE PESQUISA EM GEOGRAFIA FÍSICA - PROGRAMA DE PÓS-GRADUAÇÃO EM GEOGRAFIA FÍSICA-USP, 3, 2006. São Paulo, Anais..., São Paulo: USP, p. 91-102, 2006b, cd-rom.

FIALHO, E. S. Ilha de calor em cidade de pequeno porte: Caso de Viçosa, na Zona da Mata Mineira. 248f. Tese (Doutorado em Geografia Física), Faculdade de Filosofia, Letras e Ciências Humanas, Programa de Pós-graduação em Geografia Física, USP, 2009.

FLANNERY, T. Os senhores do clima. Rio de Janeiro: Record, 2007, 388p.

JAUREGUI, E. The urban climate of Mexico city. Erdkunde, Berlin, v. 27, p. 289$307,1973$.

GOLDREICH, Y. Urban climate studies in Johannesburg: A sub-tropical city located on a ridge: Review. Atmospheric environment, London, v. 26b, n. 3, p. 407-420, 1992.

MASSON, V. Urban surface modeling and the meso-scale impact cities. Theoretical and applied climatology, Viena, v. 84, n. 1-3, p. 35-45, 2006.

MENDONÇA. F. A. ; CANALI, N. E. ; SANTOS, C. D. T.; MAXIMIANO, L. A.; GRIGIO, A. M. Evolução e Tendências da geografia Física no Brasil. In: SIMPÓSIO BRASILEIRO DE GEOGRAFIA FÍSICA APLICADA, 7. Belo Horizonte, p. 523-524, 1999.

MONTEIRO, C. A. F. El estudio de los climas urbanos en las regiones tropicales de America del sur: La contribución brasileña In: PROCEEDINGS TECH. CONFERENCE URBAN CLIMATOLOGY AND ITS APPLICATIONS WITH SPECIAL REGARD TO TROPICAL AREAS, Mexico City, Mexico, 22p. 1984.

MONTEIRO, C. A. F. O homem, a natureza e a cidade: Planejamento do meio físico. Revista eletrônica geografar, Curitiba, v. 3, n. 1, p. 73-101, 2008. 
RIBEIRO, C. M. O Desenvolvimento da climatologia dinâmica no Brasil. Revista geografia e ensino. Belo Horizonte, v. 1, n. 2. p. 48-59, 1982.

- Para a discussão sobre uma climatologia geográfica. Caderno de geografia. Belo Horizonte, v. 14, n. 23, p. 95-102, 2004.

SANT'ANNA NETO, J. L. Contribuição à história da climatologia no Brasil. In: SIMPÓSIO BRASILEIRO CLIMATOLOGIA GEOGRÁFICA, 5, Paraná, Anais... Curitiba: UFPR, p. 1161-1170, 2002. cd-rom.

SANTOS, M. J. Z. Tendências dos estudos climáticos e bioclimáticos no Brasil. Boletim de geografia teorética, v. 15, n. 29-30, p. 45-52, 1985.

SIMPÓSIO BRASILEIRO DE CLIMATOLOGIA GEOGRÁFICA, 1., 1992, Rio Claro. Anais... Rio Claro: UNESP, 1992, 80p.

SIMPÓSIO BRASILEIRO DE CLIMATOLOGIA GEOGRÁFICA, 2., 1996, Presidente Prudente. Anais... Presidente Prudente: UNESP, 1996, 65p.

SIMPÓSIO BRASILEIRO DE CLIMATOLOGIA GEOGRÁFICA, 3., 1998, Salvador. Anais... Salvador: UFBA, 1998, 50p.

SIMPÓSIO BRASILEIRO DE CLIMATOLOGIA GEOGRÁFICA, 4., 2000, Rio de Janeiro. Anais... Rio de Janeiro: Climageo/Crea-RJ, 2000, 75p.

SIMPÓSIO BRASILEIRO DE CLIMATOLOGIA GEOGRÁFICA, 5., 2002, Curitiba. Anais... Curitiba: UFPR, 2002. cd-rom.

SIMPÓSIO BRASILEIRO DE CLIMATOLOGIA GEOGRÁFICA, 6., 2004. Aracajú. Anais... Aracajú: UFSE , 2004, 190p.

SIMPÓSIO BRASILEIRO DE CLIMATOLOGIA GEOGRÁFICA, 7., 2006. Rondonópolis. Anais... Rondonópolis: UFMT, 2006, 257p.

SIMPÓSIO BRASILEIRO DE CLIMATOLOGIA GEOGRÁFICA, 8., 2002, Alto do Caparaó. Anais... Minas Gerais: UFU, 2008. cd-rom.

SOUZA, M. B.; FURLAN, S. A. Trajetórias da Geografia Física no Brasil através de eventos científicos. In: ENCONTRO DE GEÓGRAFOS DA AMÉRICA LATINA, 10, São Paulo, Anais... São Paulo: USP, p. 15390-15405, 2005. cd-rom.

ZAVATINI, J. A. Desenvolvimento e perspectivas da climatologia geográfica no Brasil: O enfoque dinâmico, a noção de ritmo climático e das mudanças climáticas. In: SANT'ANNA NETO, J. L.; ZAVATINI, J. A. (org.).: Variabilidade e mudanças climáticas: Implicações ambientais e socioeconômicas. Maringá: Eduem, p. 225-249, 2000.

ZAVATINI, J. A. O tempo e o espaço nos estudos do ritmo do clima no Brasil. Geografia, Rio Claro, v. 27, n. 3, p. 101-131, 2002. 